\title{
THE STUDY OF HEAT ISLAND AND ITS RELATION WITH URBANIZATION IN GURUGRAM, DELHI NCR FOR THE PERIOD OF 1990 TO 2018
}

\author{
S. Kushwaha ${ }^{1}$, Y. Nithiyanandam² \\ ${ }^{1}$ Department of Natural Resources, TERI School of Advanced Studies, New Delhi, India- skrsgis@ protonmail.com \\ ${ }^{2}$ Department of Natural Resources, TERI School of Advanced Studies, New Delhi, India- nithirsgis@ gmail.com
}

KEY WORDS: Satellite towns, Urban Heat Island (UHI), Land surface temperature, Urbanization, Gurugram

\begin{abstract}
:
Rapid growth in population and land cover makes urban areas more vulnerable to Urban Heat Island. Due to which, cities experience higher mean temperature than its proximate surrounding rural or non-urban area. The relationship between UHI and urbanization is proven in previous studies. Delhi the capital city of India is well known for its extreme heat condition in summer and air pollution. In this study, an attempt has been made to understand UHI behavior in a satellite town of Delhi. Satellite town or cities are the small independent towns built in the vicinity of a large city or metropolitan city. In this paper 4 major satellite towns of Delhi, i.e. Gurugram (name changed from Gurgaon in April 2016), Noida, Faridabad and Ghaziabad has been studied to understand the changing trends in urbanization and temperature. The parameters used are rate of urban expansion, population density, GDP growth and increasing temperature over the last two decades. Gurugram showed the maximum urbanization and identified as study area. Gurugram has undergone a major growth journey from being a small town to 'The Millennium city' of the country in a short span. The Landsat images of past three decades ranging from different time period i.e. 1990, 1996, 2002, 2009, 2014 and 2018 were investigated by applying integrated approach of GIS and Remote sensing. The images represent the condition of UHI and urbanization in different period. The temporal change in LULC was used to study the rate of urban growth in last three decades. The results showed the increase in built-up area out of the total area of Gurugram from $10 \%$ (i.e. $50.6 \mathrm{sq} . \mathrm{km}$ ) in 1990 to $17.25 \%$ (80.5 sq. km) in 2002 which further increased to $45.1 \%$ (210.4 sq. $\mathrm{km}$ ) in 2018. Thermal Infrared band of Landsat series were used to retrieve land surface temperature (LST) intensity of the study period. The results show a positive correlation $(\mathrm{r}=0.46)$ between impervious surfaces and LST. The results of the study could be helpful in identifying the causative factors and level of impacts in different zones and also enable us to develop a mitigation strategy based on spatial decision support system.
\end{abstract}

\section{INTRODUCTION}

Urban heat islands is the one of the critical challenge in the growing world. Urbanization and industrialization leads to the improved comfortable and material life. But with this increased comfort brings the problems like global warming, increased pollution and urban heat islands etc. Changes happens in landscape with the development in urban areas. With the urbanization, buildings, roads and other infrastructure replaces the open land and vegetation. Surfaces that were once permeable and moist becomes impermeable and dry. This development leads to the formation of urban heat islands (United States Environmental Protection Agency, 2008). Concretization and reduction in vegetation cover alters the pattern of surface temperature. This alteration of the temperature that is warmer than neighbouring non-urban is UHI (Voogt \& Oak, 2003). The expansion in urban population from $30 \%$ of the total population of the world in 1950 to $55 \%$ in 2018 and which is further expected to be $68 \%$ by 2050 (United Nations, 2018]. The population of cities in India constitute $32 \%$ of total population and is projected for further increase rapidly by 2050 owing to continuous migration from rural areas (United Nations, 2014).

Urban Heat Island (UHI) phenomenon was first documented by Howard in 1883 while studying the climate of London. Since then several studies have been conducted over the years to understand the phenomenon of UHI, its spatial variability and its impact. Study by Kim (1992) on UHI indicated that the urban heating is attributable to a great extent on excess in heat due to rapidly heating urban surfaces that primarily consist of buildings, asphalt, bare-soil and short grasses. The symptoms of such diurnal heating in summer begins to appear by mid-morning and can go about $10^{\circ} \mathrm{C}$ warmer than the nearby woodlands (Wilby, 2008).
The advancement in the technology of remote sensing made it possible to spot and detect the changes happening. Thermal infrared data acquired by satellite was firstly used by Rao in 1972 to analyse the urban area temperatures. For measuring UHIs, land surface temperature can be a criterion (Voogt \& Oak, 2003). There is a strong linear relationship between Land surface temperature and impervious surface (Yuan \& Bauer, 2007). Yadav et al (2017) conducted an analysis of urban built-up areas and surface urban heat island using downscaled MODIS derived land surface temperature data. Major urban heat islands were extracted from mean-monthly time series of MODIS LST data sets for the time period from 2010 to 2015 . A study by Xu \& Chen (2004) for Xiamen of China using remote sensing technology between the years 1989 and 2000 showed obvious evidence on development of urban heat islands in those 11 years through change detection analysis of the satellite images.

Attempts to study impact of Urban Heat Islands were made in India. Grover and Singh in (2015) analysed the UHI relation with NDVI for Delhi and Mumbai using thermal images of LANDSAT and found a greater UHI effect in Mumbai compared to that in Delhi. Kishore Yadav and team (2016) also conducted a study on identifying urban heat islands from multi temporal MODIS land surface temperature data in southern West Bengal. Similarly, Sharma and Joshi (2014) identified seasonal heat islands in urban settings of Delhi using remotely sensed data. They suggested that seasonal distribution needs comprehensive study to propose appropriate mitigation measures. The UHI patterns were then also correlated with the classified land use and land cover information (Effat \& Hassan, 2014). Their study suggested that high resolution satellite images with thermal bands can be further applied to study and understand the small 
urban heat islands within a large metropolitan urban area. This would pave the way for using temperature characteristics of the cities to be identified in direct relation to the urban land use and expansion (Heinl, Hammerle, Tappeiner, \& Leitinger, 2015).

Out of world's top 10 most populous urban areas Asia has seven and Delhi being one of them (Boselli, 2011). Delhi is the capital city of India located in northern part and has monsoon influenced humid and semi-arid climatic conditions. The city has experienced a rapid urbanization especially over past two decades i.e. 1990-2010 (Mohan et. al., 2011).Delhi has been a piece of attention for researchers since long but satellite towns have much been ignored (Bhullar AK, 2014). The present study aims to understand the behaviour of UHI in a satellite town of Delhi. The satellite towns are the small independent towns built in the vicinity pf a large city. Delhi has four major Satellite towns, i.e. Gurugram, Noida, Faridabad and Ghaziabad. Out of these Gurugram was chosen and studied to see the influence of UHI over a period of 3 decades. Based on certain parameters like rate of urban expansion, population density, and GDP growth and increasing temperature in past two decades, the study area was chosen. Through this paper an attempt has been made to examine the extent of urbanization and intensity of UHI over a period of 3 decades in Gurugram, also how the heat intensity is related with impervious surface.

\section{SATELLITE TOWNS AND STUDY AREA}

\subsection{The major satellite Towns of Delhi:}

The major satellite towns of Delhi are Gurugram, Noida, Ghaziabad and Faridabad which shares the increased socioeconomic weight of highly urbanized Delhi.

\subsection{Parameters used to identify Study Area:}

The objective of the study is concerned with a phenomena which is the result of population growth, urban area (built-up) growth and other factors. For selection of study area, two main criteria are adopted, which have a direct and strong relation with the prevalence of any anthropogenic activity in the urban areas. First among them is the population growth, second the extent of urbanization in terms of built-up area. Third parameter economic growth. Urbanization is full of economic implications. There is a close liaison between urbanization and economic development. It exercises a perceptible influence on the process of capital formation, i.e., saving and investment and on industrialization. Studies have shown that transformation of land surface are into concrete and asphalt area leads to the increased land surface temperature, so the fourth and fifth parameters taken are LST which is extracted using remote sensing and annual mean temperature trend. The period of two decades i.e. 1999-2018 has been taken for the comparative study. Following are the parameters used to identify the study area:

2.2.1 Built-Up areas for the study of urban expansion: Using Landsat images of year 1999, 2009 and 2018, the growth of built up area was observed. In Gurugram $62.02 \mathrm{sq}$. km area had been converted into impervious during 1999 to 2009 which further increased by $87.42 \mathrm{sq} \mathrm{km}$ in next decade i.e. from 20092018. During 1999 to 2009, Ghaziabad saw $41.19 \mathrm{sq} \mathrm{km}$, Noida $26 \mathrm{sq} \mathrm{km}$ and Faridabad $14.67 \mathrm{sq} \mathrm{km}$ of expansion of the total areas of respective towns. The trend in next decade changed a bit showing a less expansion in Ghaziabad (23.86 sq km), and increase in Noida (50.6 sq km) and Faridabad (44.19 sq km).



Figure 1. Graph showing growth in Built-up area over years

2.2.2 Population Growth: Decadal growth rate of population (2001-2011) showed the higher growth in Gurugram. Figure 2 shows the $73.9 \%$ of growth in population while other satellite towns showed a decreased trend.

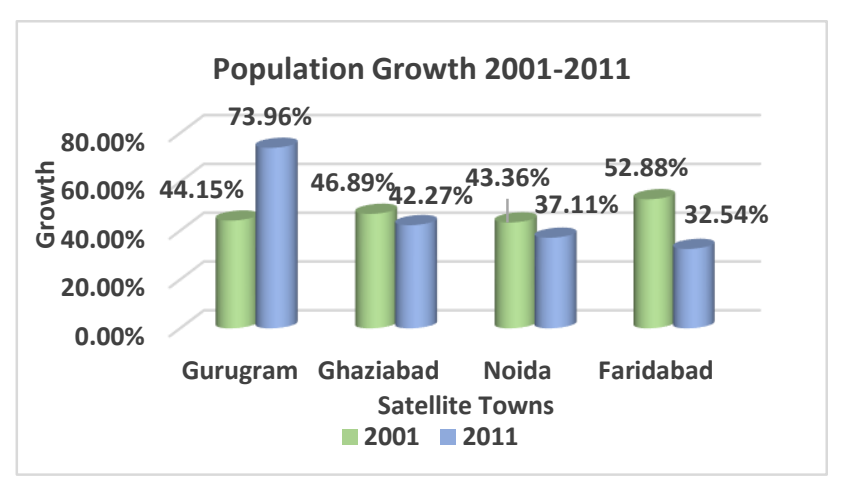

Figure 2.Decadal growth of population

2.2.3 Gross value added (GVA), a measure of economic development: It is a measure of total output and income in the economy. It provides the rupee value for the amount of goods and services produced in an economy after deducting the cost of inputs and raw materials that have gone into the production of those goods and services. It also gives sector-specific picture like what is the growth in an area, industry or sector of an economy. Figure 3 and Figure 4 shows the highest GVA in Gurugram.

Per Capita GVA (Current Prices) in Rs. Million, from 2011-2018

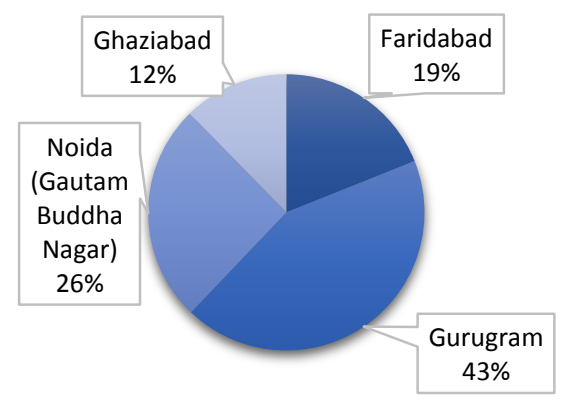

Figure 3. Per capita GVA 


\section{Total Gross Value Added (Constant Prices) in Rs. Millions, from $2011-2018$}

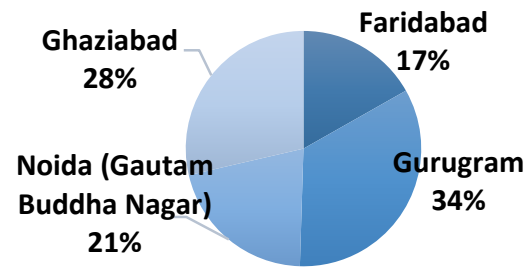

Figure 4. Total GVA

2.2.4 Land surface temperature: The LST was derived using thermal infrared bands using the methodology explained in section 4. The result (Figure 5) showed increasing trends Faridabad and Ghaziabad while for Gurugram and Noida LST was higher in 2009 which in 2018 decreased .Overall the higher heat intensity can be seen in Gurugram, also the fall in temperature is more in Gurugram.

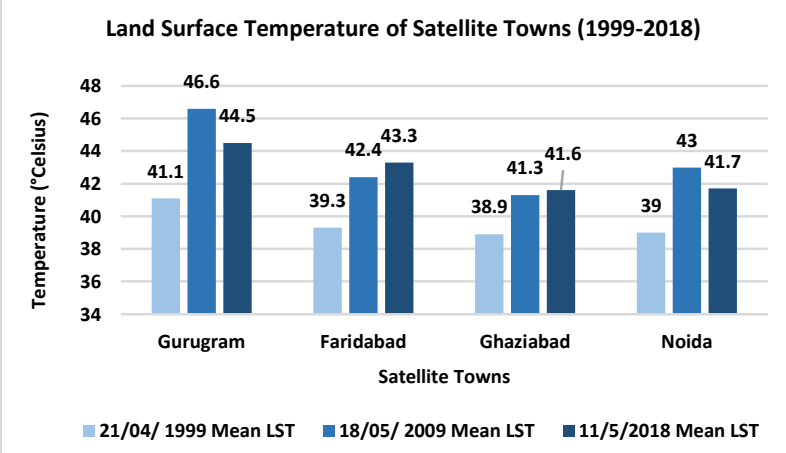

Figure 5. LST of satellite towns

2.2.5 Temperature trends: Figure 6, 7, 8 showing the average annual, maximum and minimum temperature for year 1999-2018. The trend is increasing and Gurugram showing the maximum increase.

Average Temperature Change (1999-2018)

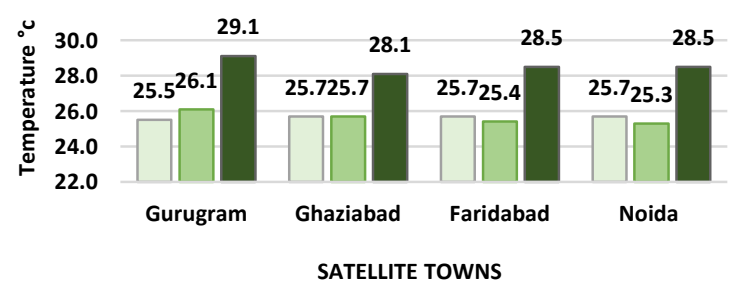

$\square 1999$ mean temp $\square 2009$ mean temp $\square 2018$ mean temp

Figure 6.Graph showing Annual average temperature

Maximum Temperature Change (1999-2018)

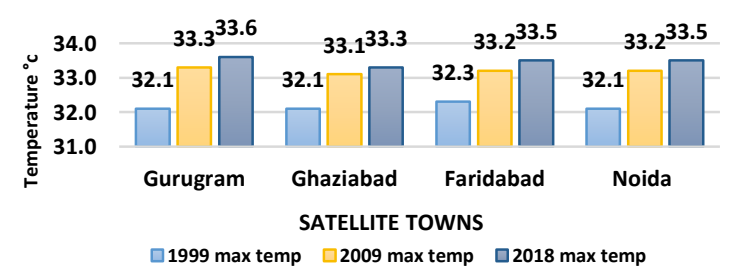

Figure 7. Change in Maximum temperature over 20 years
Minimum Temperature Change (1999-2018)

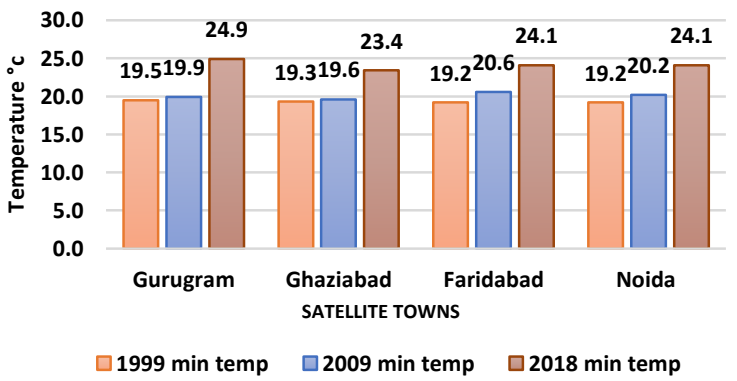

Figure 8. Change in Minimum temperature of Towns

Based on all the above parameters Gurugram has been chosen to understand the rise and fall of temperatures and intensity of heat in this satellite town.

\subsection{Study Area}

Gurugram is a highly vibrant city in northern India in the state of Haryana. Located 32 kilometres southwest from New Delhi, it is part of the National Capital Region. The population of Gurgaon as per 2011 Census is 876,824 . Gurugram has been one of the fastest growing Urban Centres and also represents a successful model of economic hub in the country (Anand et al., 2015). It is a leading financial and industrial hub with the third-highest per capita income in India (Julka, Harsimran, 2011).

With economic liberalization and globalization in 1990s, Gurugram has become a home numerous job options, which results in immigration of huge population in the city giving it a growth spurt. Basically private sector led urbanization (Mehtani et. al., 2013). The city has overlap between monsoon-influenced humid subtropical and semi-arid climate is now increasingly becoming hotter with extreme temperatures in summer (Chun, Kwok, Mitamura, Miwa, \& Tamura, 2008; Hulme \& Viner, 1998).

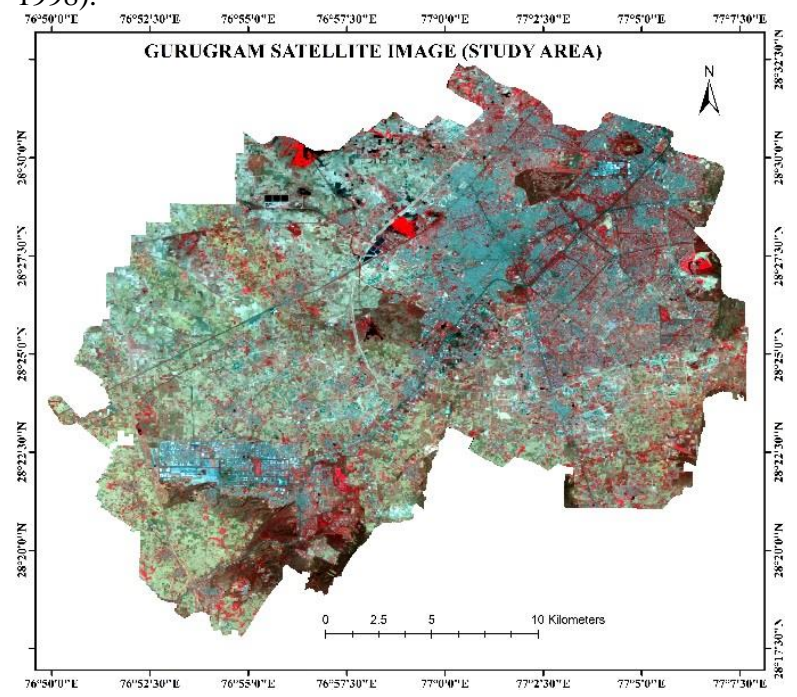

Figure 9. Satellite image of Study Area

\section{DATA USED}

The satellite data used were downloaded from http://earthexplorer.usgs.gov/.Landsat 5 TM, Landsat 7 ETM+ 
and Landsat 8 OLI_TIRS imageries of good quality ( 0 cloud cover) having $30 \mathrm{~m}$ spatial resolution has been used for this study. The original digital numbers of band 6 (thermal infrared band) of Landsat TM and ETM and band 10 (thermal infrared band) of Landsat 8 were then converted to at-satellite radiance to retrieve the brightness temperature.The spa Regional and master plans for the cities for the year 2031 from different sources on internet has been used. Google earth imagery were also used. Long term temperature data was taken from https://www.indiawaterportal.org and https://www.worldweatheronline.com. Also the census data was from census of India website.

\begin{tabular}{|c|c|c|c|c|}
\hline Year & Image Name & Date & Row & Path \\
\hline 1990 & Landsat 5 TM & $21 / 05 / 1990$ & 40 & 147 \\
\hline 1996 & Landsat 5 TM & $5 / 5 / 1996$ & 40 & 147 \\
\hline 2002 & Landsat 7 ETM+ & $8 / 6 / 2002$ & 40 & 146 \\
\hline 2009 & Landsat 5 TM & $18 / 05 / 2009$ & 40 & 146 \\
\hline 2014 & Landsat 8 OLI_TIRS & $16 / 05 / 2014$ & 40 & 146 \\
\hline 2018 & Landsat 8 OLI_TIRS & $11 / 5 / 2018$ & 40 & 146 \\
\hline
\end{tabular}

Table1. Satellite data used

\section{METHODS}

\subsection{Image pre-processing}

The images used are of highest quality (L1TP) which is systematically, radiometrically, geometrically and topographically corrected using GCPs. Only stacking and subsetting was done.

\subsection{Image Analysis and Parameters extraction}

To examine the extent of urbanization on a regional scale, land use land cover classification is an important method which helps in detecting changes happened over years. After image preprocessing supervised classification was carried out. The image was classified using maximum likelihood classifier technique. In this technique the pixels are assigned based on the highest probable class. The image was classified into 5 classes: impervious/built-up areas, vegetation/green cover, water bodies, agricultural land and other (rocks, wasteland etc.).Further from the classified image built -up area was extracted by reclassification.

\subsection{Image post-processing}

For the study a new Reflectance based emissivity technique has been used as emissivity is a significant factor for LST derivation (Y. Nithiyanandam, 2016). To extract the land surface temperature from satellite imageries, thermal infrared (TIR) bands are used. For Landsat TM and ETM, TIR band is band 6 with spectral range from $10.4-12.5 \mu \mathrm{m}$, and for Landsat $8 \mathrm{OLI}$ TIRS band 10 with spectral range from 10.6 to $11.9 \mu$ m have been used for the present study. The steps used to derive land surface temperature are shown in Figure 11.

4.3.1 Conversion of Digital number (DN) to Spectral radiance: Eq. (1) has been used to convert DN values into spectral radiance.

$$
\mathrm{L}_{\mathrm{rad}}, \mathrm{x}=\mathrm{UCC}_{\mathrm{x}}\left(\mathrm{DN}_{\mathrm{x}}-1\right)
$$

Where,

$\mathrm{L}_{\mathrm{rad}}=$ spectral radiance of band $\mathrm{x}$,

$\mathrm{UCC}_{\mathrm{x}}=$ unit conversion coefficient of band $\mathrm{x}$

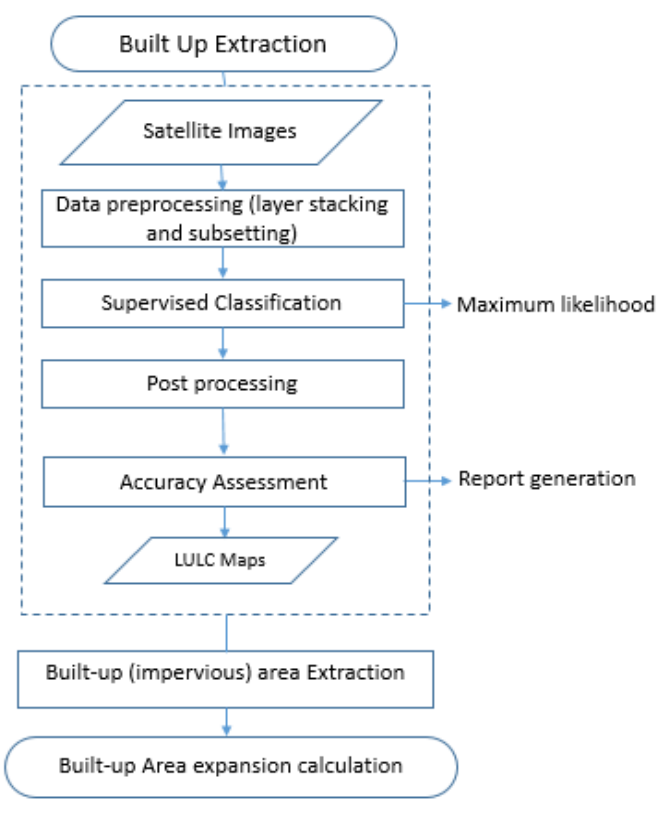

Figure 10. Methodology to Map extent of Urbanization

The UCC value for each band represents the gain setting used during image acquisition, which can be known from the header file associated.

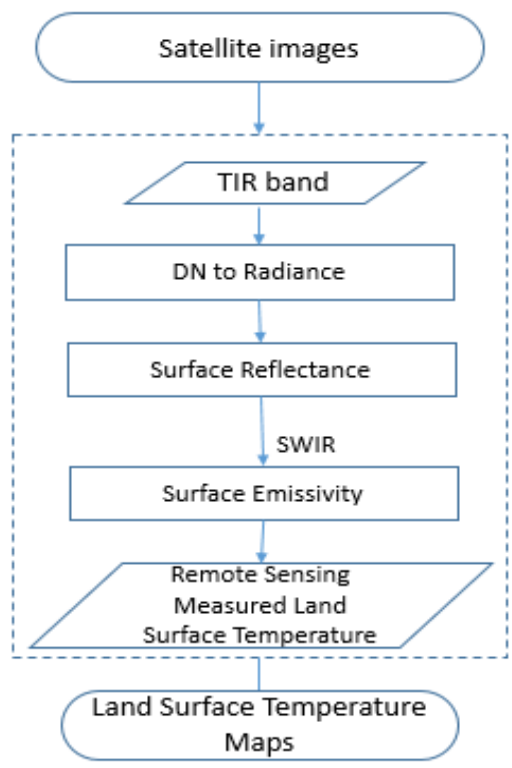

Figure 11. Flow Chart for Land surface Temperature

\subsubsection{Conversion from radiance to LST:}

a) Calculation of at-sensor Brightness Temperature: The thermal band (Band-13) is converted from at sensor spectral radiance to at-sensor $\mathrm{B}_{\mathrm{T}}$, assuming that the Earth's surface is a black body (i.e., spectral emissivity equals 1) and atmospheric effects (absorption and emission along the path) have been taken into account (Chander et al., 2009). The conversion formula for estimating at-sensor $\mathrm{B}_{\mathrm{T}}$ from at-sensor spectral radiance is:

$$
\mathrm{B}_{\mathrm{T}}=\frac{K_{2}}{\ln \left(\frac{K_{1}}{L_{\lambda}}+1\right)}
$$


Where,

$\mathrm{B}_{\mathrm{T}}=$ At-sensor Brightness Temperature $(\mathrm{K})$,

$\mathrm{L}_{\lambda}=$ At-sensor radiance, $\ln =$ Natural $\log$

$\mathrm{K}_{1}$ and $\mathrm{K}_{2}=$ Calibration Constants

Values of $\mathrm{K}_{1}$ and $\mathrm{K}_{2}$ are as follows:

\begin{tabular}{|c|c|c|c|}
\hline & Landsat TM & Landsat ETM & Landsat 8 \\
\hline $\mathrm{K}_{1}$ & 607.76 & 666.09 & 774.89 \\
\hline $\mathrm{K}_{2}$ & 1260.56 & 1282.71 & 1321.08 \\
\hline
\end{tabular}

b) Since the measured LST values are referenced to a blackbody, it is necessary to correct for spectral emissivity with respect to the thermal properties of the urban surface material in question. The emissivity corrected LST $(T \varepsilon)$ are calculated using the following equation (Artis and Carnahan, 1982; Weng et.al., 2008)

$$
\mathrm{T} \varepsilon=\frac{B_{T}}{1+\left(\lambda * B_{T} / \rho\right) \ln \varepsilon_{S}}
$$

Where,

$\lambda=$ Peak response wavelength of emitted radiance

$\mathrm{B}_{\mathrm{T}}=$ At-sensor Brightness temperature

$\rho$, the flux density $=[\mathrm{h} \times(\mathrm{C} / \sigma)]=1.438 \times 10^{-2} \mathrm{~m} \mathrm{~K}$, $\varepsilon_{\mathrm{s}}=$ Surface emissivity, $\mathrm{h}=$ Planck's constant $(6.626 \times 10-34 \mathrm{~J} \mathrm{~s})$, $C=$ Velocity of light $(2.998 \times 108 \mathrm{~m} \mathrm{~s}-1), \sigma=$ Boltzmann constant $(1.38 \times 10-23 \mathrm{~J} \mathrm{~K}-1)$.

\section{RESULTS AND DISCUSSIONS}

In Gurugram, settlements and impervious areas has increased rapidly from 1990 to 2018. The changes in land use and land cover has detected using remote sensing technique. Supervised classification was done to detect the temporal changes. Result of this classification showed increase in built up area.

\begin{tabular}{|c|c|c|}
\hline Year & $\begin{array}{c}\text { Accuracy } \\
\text { Percentage }\end{array}$ & Kappa coefficient \\
\hline 1990 & $87.50 \%$ & 0.83 \\
\hline 1996 & $95.00 \%$ & 0.93 \\
\hline 2002 & $95.00 \%$ & 0.93 \\
\hline 2009 & $86.67 \%$ & 0.83 \\
\hline 2014 & $90.00 \%$ & 0.88 \\
\hline 2018 & $93.33 \%$ & 0.91 \\
\hline
\end{tabular}

Table2. Accuracy assessment of land use classification of Gurugram.

The total built up (Impervious Area) in 1990 was $10.9 \%$ which grew to $17.25 \%$ in 2002 and by 2018 increased to $45.17 \%$ of the total area. In Figure 12 bar graph is depicting a continuous increasing trend.This is showing a rapid urbanization has taken place in Gurugram over the period of years. The concretization is almost 4 times in 3 decades and increased population indicates the rapid growth of Gurugram into an urbanized town.

Urbanization has a negative impact on environment. Increased pollution and changes in physical as well as chemical properties are the impacts of this urbanization. Impervious area/ built-up areas absorb large amount of radiation and since material used in construction are water resistant and non-reflective the radiations absorbed trapped are released slowly in the form of heat which results in higher surface temperature. The open lands have very low emissivity that is why open lands also shows high LST, but this is not harmful as radiations falls it reflects back immediately. Figure 13 illustrates the temporal change in land surface temperature in Gurugram and Figure 14 shows temperature change of impervious/built-up area. It indicated an overall increase in heat intensity. There is an increase of 8 degree Celsius in temperature from 1990 to 2018 . It is also found that there is a positive correlation between impervious area and Land surface temperature $(r=0.46)$, which means that with the increase in impervious area heat intensity also increased.

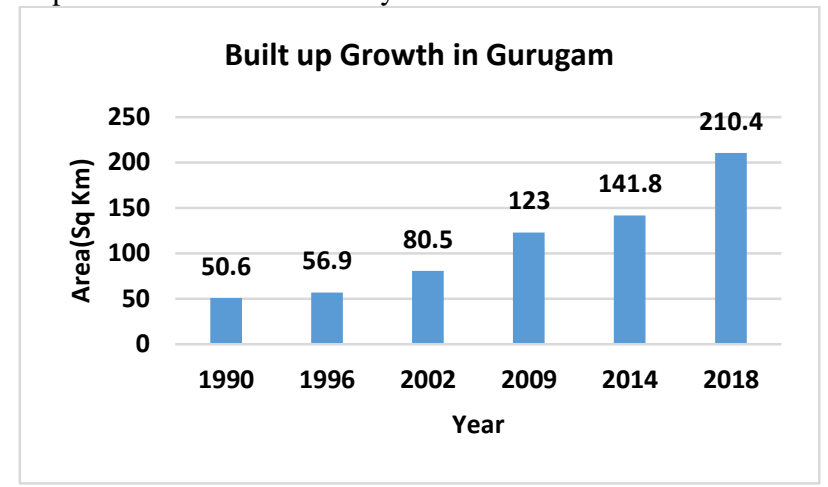

Figure 12. Bar graph showing temporal change in built-up area.

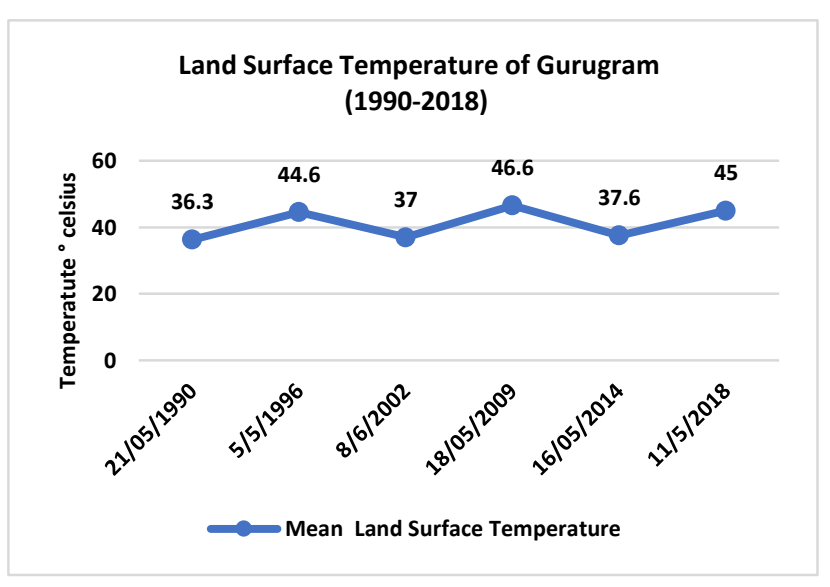

Figure 13. Temporal Land Surface Temperature

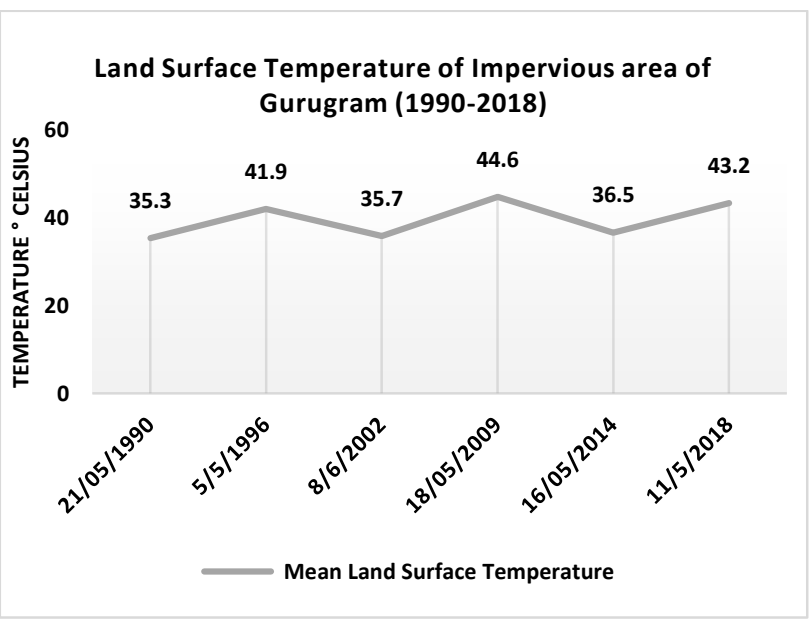

Figure 14. Graph showing LST Of Built-Up/Impervious

The historical temperature data (Figure 15, 16, 17) also proves that the heat intensity in this satellite town has been increasing. The annual minimum temperature is increasing constantly. The trend shows an overall approximately 6 degrees Celsius rise over past 28 years. Not only summers, winters also becoming warm. The minimum and maximum temperatures are rising constantly. 
The rise in minimum temperature leading increased heat and discomfort. This is due to increased anthropogenic activities and increased impervious areas.

Average temperature trend in Gurugram (1990-2018)

40.0

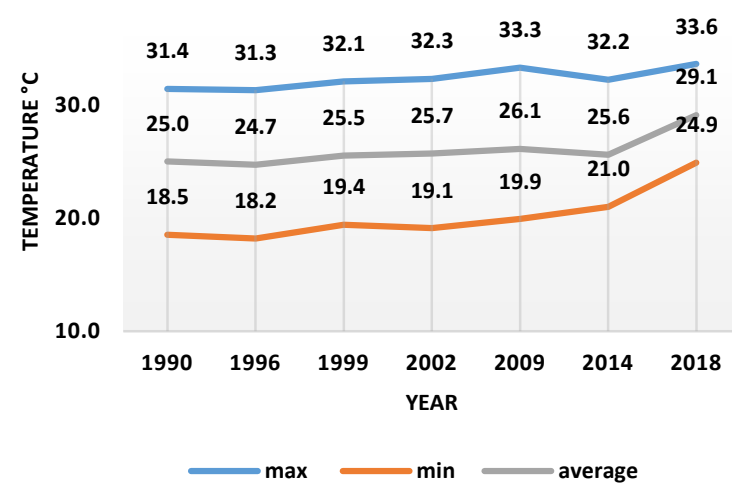

Figure 15. Annual temperature from 1990-2018

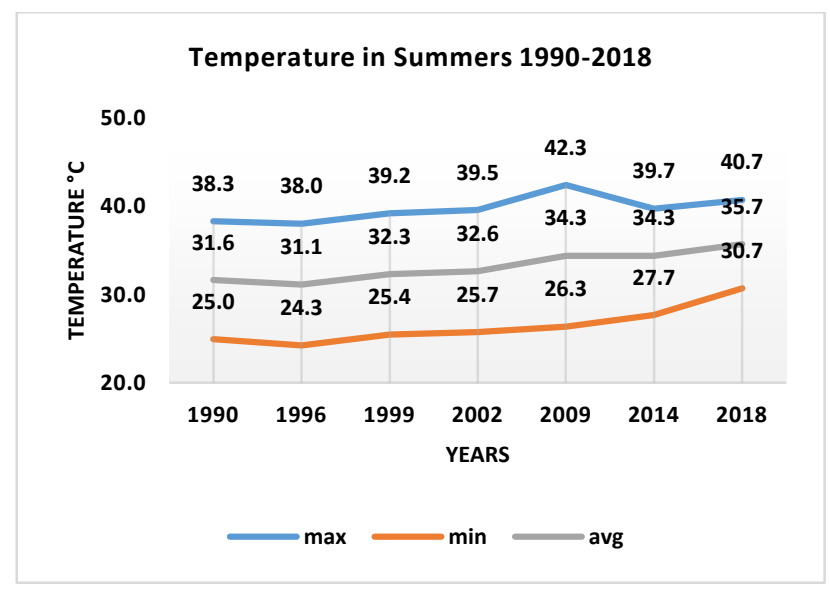

Figure 16. Summer Temperature from 1990-2018

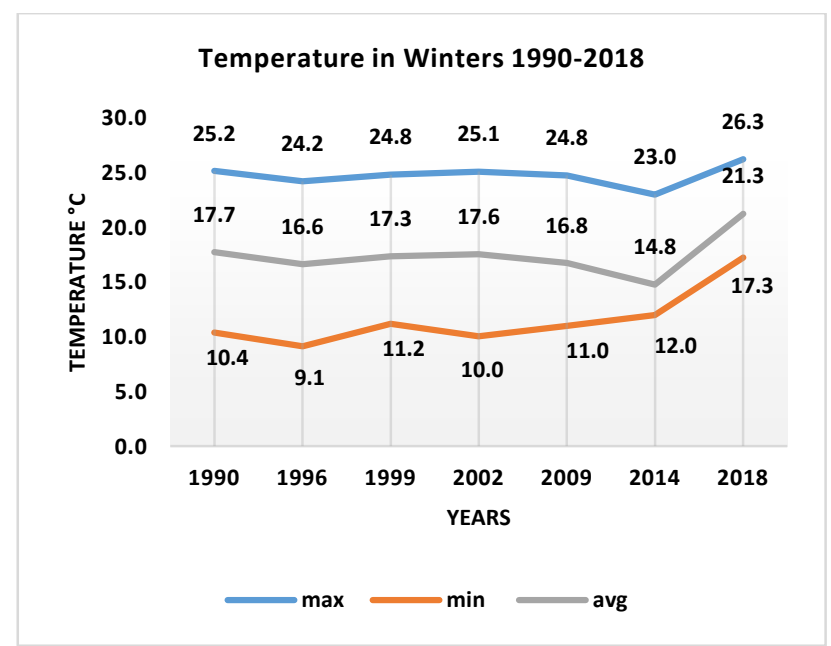

Figure 17. Winter Temperature from 1990-2018

\section{CONCLUSION}

In the study out of four major satellite towns of national capital Delhi Gurugram was selected based on certain parameters. The criteria were all related to urbanization which is one of the major cause of Urban Heat Islands. Gurugram has shown rapid urbanisation and increased population. The land use/Land cover change over the period from 1990 to 2018 showed rapid increase in built-up/ impervious areas. These changes were also accompanied by the changes in LST and overall temperature. The trend showed rise in mean LST by 8 degrees Celsius and 6 degrees Celsius in minimum temperature of Gurugram from 1990 to 2018. The study made it possible to examine the impacts of urbanization on the heat intensity. The data used to find out temporal change in Land use land cover is of coarse spatial resolution which made it hard to identify building type and resulted in some loss of information. The study is of utmost importance for the climate change and the unplanned urbanization issues. The study can help to understand the development of UHI Zones and monitor the UHI patterns and impacts, which can be used as baseline information for defining the thermal comfort and microclimatic patterns. Thermal discomfort occurs due to increased heat and the related health problem can be studied in a UHI affected area, which can be further used to develop spatially enabled UHI mitigation strategies to manage the health hazard as well as climate change.

\section{REFERENCES}

Artis, D.A., \& Carnahan, W.H., 1982. Survey of emissivity variability in thermography of urban areas. United States. doi:10.1016/0034-4257(82)90043-8.

Bhullar, AK., 2014. Landscape Configuration and Thermal Environments of central National Capital Region. Masters of technology thesis, Andhra University.

Boselli, B. e. a., 2011. Asian Green City Index.Munich, Germany, Economist Intelligence Unit

Chander, G., Markham, B.L., \& Helder, D.L., 2009. Summary of current radiometric calibration coefficients for Landsat MSS, TM, ETM+, and EO-1 ALI sensors. Remote Sensing of Environment, 113, 893-903

Chun, C., Kwok, A., Mitamura, T., Miwa, N., \& Tamura, A., 2008. Thermal diary: Connecting temperature history to indoor comfort. Building and Environment, 43(5), 877-885. doi.org/10.1016/j.buildenv.2007.01.031

Effat, H. A., \& Hassan, O. A. K., 2014. Change detection of urban heat islands and some related parameters using multitemporal Landsat images; a case study for Cairo city, Egypt. Urban Climate, 10(P1), 171-188. doi.org/10.1016/j.uclim.2014.10.011

Grover, A., \& Singh, R., 2015. Analysis of Urban Heat Island (UHI) in Relation to Normalized Difference Vegetation Index (NDVI): A Comparative Study of Delhi and Mumbai. Environments, 2(2), 125-138. doi.org/10.3390/environments2020125

Heinl, M., Hammerle, A., Tappeiner, U., \& Leitinger, G., 2015. Determinants of urban-rural land surface temperature differences - A landscape scale perspective. Landscape and Urban Planning, 134, 33-42.doi.org/10.1016/j.landurbplan.2014.10.003 
Hulme, M., \& Viner, D., 1998. A climate change scenario for the tropics. Climatic Change, 39(2-3), 145-176. doi.org/10.1023/A:1005376007729

Ichinose, T., Shimodozono, K., \& Hanaki, K., 1999. Impact of anthropogenic heat on urban climate in Tokyo. In Atmospheric Environment (Vol. 33, pp. 3897-3909).doi.org/10.1016/S13522310(99)00132-6

Julka, Harsimran (30 September 2011). "IT firms looking beyond Gurgaon, Noida, Greater Noida to other cities in north India". The Economic Times. ET Bureau. Archived from the original on 5 November 2013. Retrieved 2 October 2013

Kim, H. H., 1992. Urban heat island. International Journal of Remote Sensing, 13(12), 23192336.doi.org/10.1080/01431169208904271

Kishore Yadav, N., Santra, A., \& Samanta, A., 2016. IDENTIFICATION OF URBAN HEAT ISLANDS FROM MULTI TEMPORAL MODIS LAND SURFACE TEMPERATURE DATA IN THE SOUTHERN PART OF WEST BENGAL, INDIA. INTERNATIONAL JOURNAL OF ENGINEERING SCIENCES \& RESEARCH TECHNOLOGY, 5, 640-645.

Kumari, Madhuri., 2017. A GIS Based Study of Urbanization Impact on Land Surface Temperature in Greater Noida, India. International Journal for Research in Applied Science and Engineering Technology. V. 608-615. 10.22214/ijraset.2017.9089.

Mehtani,PC. , De, Aparajita., 2013. retrieved from:https://shodhganga.inflibnet.ac.in/bitstream/10603/26624/ 10/11_chapter\%202.pdf

Mohan, M., Kandya, A., Battiprolu, A., 2011. Urban Heat Island Effect over National Capital Region of India: A Study using the Temperature Trends. Journal of Environmental Protection, Vol. 2 No. 4, 2011, pp. 465-472. doi: 10.4236/jep.2011.24054

Nithiyanandam, Y \& Nichol, Janet., 2016. A SIMPLE AND EFFECTIVE RETRIEVAL OF LAND SURFACE TEMPERATURE USING A NEW REFLECTANCE BASED EMISSIVITY ESTIMATION TECHNIQUE. ISPRS International Archives of the Photogrammetry, Remote Sensing and Spatial Information Sciences. XLI-B8. 443-447. 10.5194/isprsarchives-XLI-B8-443-2016.

Rao, P. K. Remote sensing of urban "heat islands" from an environmental satellite. Bull. Amer. Meteor. Soc., 53: 647-648, 1972.

Sharma, R., \& Joshi, P. K., 2014. Identifying seasonal heat islands in urban settings of Delhi (India) using remotely sensed data - An anomaly based approach. Urban Climate, 9, 1934.doi.org/10.1016/j.uclim.2014.05.003

U.S. Environmental Protection Agency, 2008. "Urban Heat Island Basics." In: Reducing Urban Heat Islands: Compendium of Strategies. Draft. https://www.epa.gov/heat-islands/ heatisland-compendium

Voogt, J. ., \& Oke, T., 2003. Thermal remote sensing of urban climates. Remote Sensing of Environment, 86(3), 370384.doi.org/10.1016/S0034-4257 (03)00079-8
Weng, Q., Liu, H., Liang, B., \& Dengsheng, Lu., 2008. The Spatial Variations of Urban Land Surface Temperatures: Pertinent Factors, Zoning Effect, and Seasonal Variability IEEE Journal of Selected Topics in Applied Earth Observations and Remote Sensing, 1, 154 -166

Wilby, R. L., 2008. Constructing climate change scenarios of urban heat island intensity and air quality. Environment and Planning B: Planning and Design, 35(5), 902919.doi.org/10.1068/b33066t

Xu, H. Q., \& Chen, B. Q., 2004. Remote sensing of the urban heat island and its changes in Xiamen City of SE China. Journal of Environmental Science (China) doi.org/10.1029/2001JD001278\r10.1029/2002JD002263\r10.1 029/2002GL015295

Yuan, F., \& Bauer, M. E., 2007. Comparison of impervious surface area and normalized difference vegetation index as indicators of surface urban heat island effects in Landsat imagery. Remote Sensing of Environment, 106(3), 375-386. doi.org/10.1016/j.rse.2006.09.003

\section{APPENDIX (OPTIONAL)}

1. Built - up Maps of Gurugram

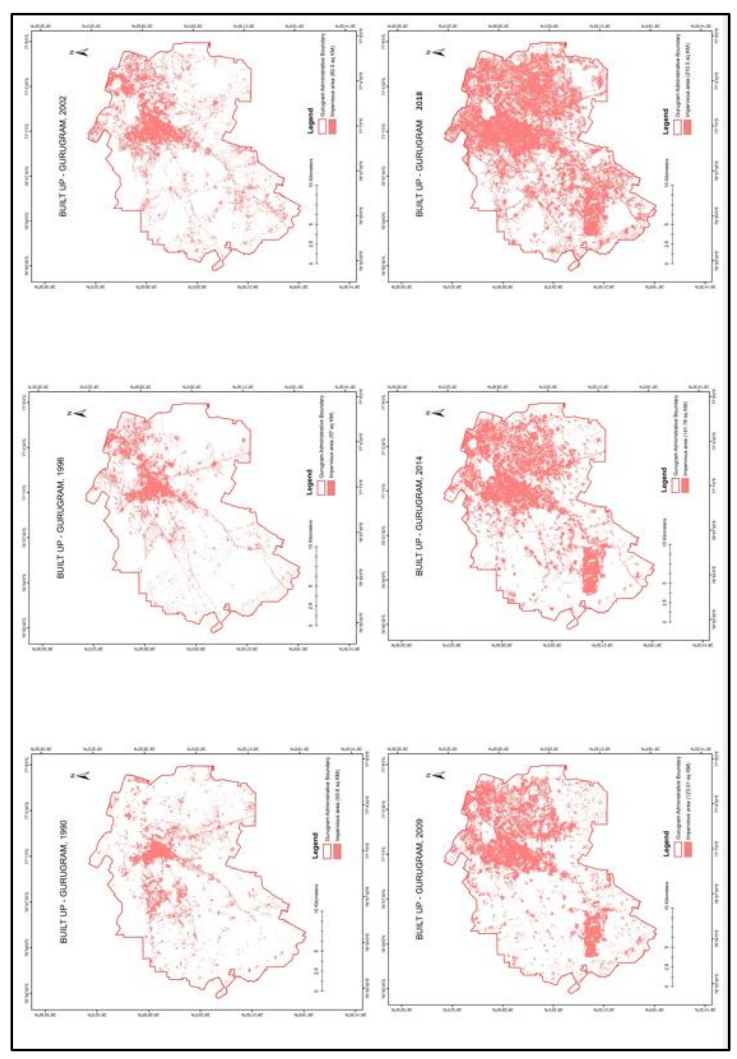




\section{Heat intensity maps of Gurugram}

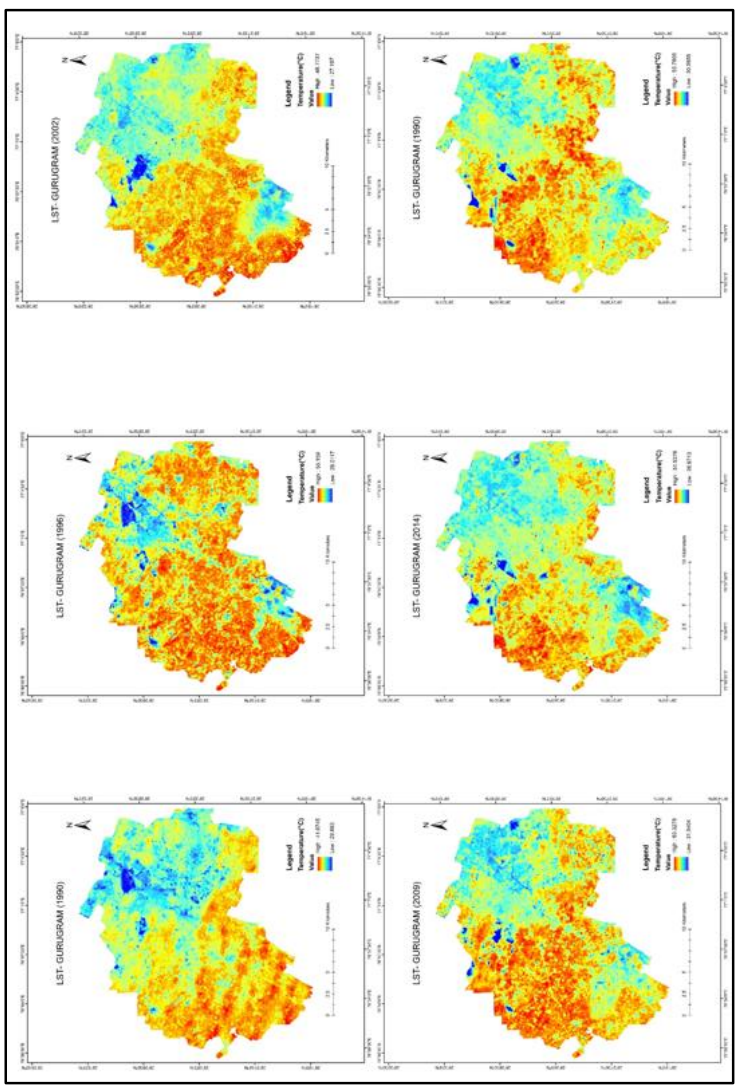

